\title{
HUBUNGAN BUDAYA MEMBACA DENGAN HASIL BELAJAR BAHASA INDONESIA PESERTA DIDIK KELAS XII SMAN 4 BANJARMASIN
}

\author{
CORRELATION BETWEEN READING CULTURE AND \\ LEARNING OUTCOMES INDONESIAN OF CLASS XII STUDENTS \\ SMAN 4 BANJARMASIN
}

\author{
Hestira Cayu Dahniar; Sainul Hermawan; Rusma Noortyani \\ Program Studi Pendidikan Bahasa dan Sastra Indonesia \\ FKIP Universitas Lambung Mangkurat \\ ecidahniar@gmail.com
}

\begin{abstract}
Abstrak
Penelitian ini bertujuan mendeskripsikan budaya membaca serta hasil pembelajar lalu mendeskripsikan hubungan budaya membaca dengan hasil belajar peserta didik di SMAN 4 Banjarmasin. Metode penelitian menggunakan metode deskriptif kuantitatif. Teknik analisis yang digunakan pada penelitian ini, yaitu korelasi product moment. Hasil analisis menunjukkan: (1) skor rata-rata budaya membaca peserta didik sebesar 108,55 dan tergolong dalam kategori sedang; (2) nilai rata-rata (mean) hasil belajar peserta didik sebesar 79,26 dan tergolong kategori sedang; (3) terdapat perolehan koefisien positif dan signifikan dengan angka korelasi sebesar 0,513. Hasil korelasi ini tergolong hubungan yang agak rendah karena angka koefisien korelasi terdapat pada selang 0.400-0.600. Berdasarkan hasil analisis di atas, Ha diambil dan Ho dibuang. Ha yang diambil dalam penelitian: ada hubungan yang baik dan relevan antara budaya membaca dengan hasil belajar Bahasa Indonesia.
\end{abstract}

Kata kunci: budaya membaca, hasil belajar

\begin{abstract}
This study aims to describe the reading culture and learning outcomes and then describe correlation between reading culture and learning outcomes at SMAN 4 Banjarmasin. The research method uses descriptive quantitative. The analysis technique used in this study is correlation product moment. The results of the analysis show that: (1) the average score of reading culture is 108.55 and in the moderate category; (2) the average score of students learning outcomes is 79.26 and in the moderate category; (3) there is positive coefficient and significance with a correlation number of 0.153. The results of this correlation are quite low because the correlation coefficient numbers are between 0.4000.600. Based on the results of the analysis above, Ha is taken and Ho was discarded. Ha taken in this study: there is a good and relevant correlation between reading culture and learning outcomes of Indonesian.
\end{abstract}

Keywords: reading culture, learning outcomes 


\section{Pendahuluan}

Kegiatan literasi merupakan satu di antara aktivitas yang penting dalam pendidikan. Untuk berhasil menyelesaikan pendidikan, budaya literasi yang baik harus ditumbuhkan. Salah satu budaya literasi yang penting untuk ditumbuhkan, yaitu budaya membaca. Membaca merupakan hal yang sangat penting dikembangkan untuk menjadi budaya.

Budaya membaca berperan penting untuk menumbuhkan kemampuan kognitif, afektif, dan psikomotorik. Seberapa banyak ilmu pengetahuan atau kemampuan kognitif yang dimiliki oleh peserta didik dalam belajar di sekolah dapat dilihat dari hasil belajar yang mereka hasilkan. Tentunya budaya membaca menjadi kunci utama terbentuknya pendidikan yang berkualitas karena dengan membaca akan didapat wawasan yang luas.

Kementerian Pendidikan dan Kebudayaan telah membuat program Lima Belas Menit Membaca sebelum belajar yang telah dijalankan pada sekolah-sekolah di Indonesia tidak terkecuali di Banjarmasin. Dalam lima belas menit, peserta didik di- perbolehkan membaca buku apa saja yang disuka, entah itu fiksi atau nonfiksi. Upaya tersebut sangat baik untuk menciptakan budaya membaca pada peserta didik. Namun, saat sekolah lain masih melaksanakan program tersebut lain halnya di SMAN 4 Banjarmasin. Program yang dibuat oleh Kemendikbud tidak dilaksanakan dengan baik oleh sekolah. Awalnya saat Kemendikbud menggalakkan Gerakan Literasi di sekolah dan programnya, yaitu lima belas menit membaca sebelum belajar, SMAN 4 Banjarmasin ikut melaksanakan kegiatan tersebut. Setelah banyaknya kewajiban yang harus dilakukan sebelum belajar, seperti menyanyikan lagu Indonesia Raya dan mengaji bersama untuk menumbuhkan pendidikan karakter, program Lima Belas Menit Membaca menjadi redup bahkan terhenti dilaksankan di sekolah tersebut.

Pada semua mata pelajaran, khususnya Bahasa Indonesia, budaya membaca menjadi sangat penting untuk dimiliki dan ditumbuhkan karena materi yang disajikan dalam mata pelajaran Bahasa Indonesia memaksa peserta didik agar membaca dan me- 
mahami dengan baik. Sudah tidak asing lagi didengar keluhan peserta didik dalam menghadapi soal-soal pelajaran Bahasa Indonesia karena memang faktanya mata pelajaran $\mathrm{Ba}-$ hasa Indonesia selalu menyajikan teks panjang yang mengharuskan peserta didik untuk membaca. Jika peserta didik menjadi malas membaca yang artinya budaya membaca tidak tumbuh dalam dirinya maka bagaimanakah peserta didik bisa mempunyai hasil belajar Bahasa Indonesia yang baik.

Menyadari pentingnya hal yang sudah dipaparkan sebelumnya maka penelitian ini akan mengetahui bagaimana budaya membaca, hasil belajar, dan hubungan kedua variabel tersebut pada kelas XII di SMAN 4 Banjarmasin. Jika tujuan penelitian ini berhasil maka akan terdapat dua manfaat, yaitu manfaat teoretis dan praktis. Manfaat teoretis dalam pe-

\section{Metode Penelitian}

\section{Jenis Penelitian}

Jenis penelitian yang digunakan adalah deskriptif kuantitatif karena akan mendeskripsikan budaya membaca dan hasil belajar Bahasa Indonesia peserta didik. nelitian ini untuk memperkaya khazanah keilmuan pada bidang pendidikan terkait hubungan budaya membaca dengan hasil belajar peserta didik Bahasa Indonesia. Sedangkan manfaat praktis penelitian ini terbagi menjadi dua, yaitu manfaat bagi para guru dan untuk sekolah. Bagi para guru penelitian ini dapat memberikan dan menambah informasi tentang bacaan yang disukai peserta didik sebagai upaya untuk membantu meningkatkan budaya membaca peserta didik kelas XII di SMAN 4 Banjarmasin. Sedangkan bagi sekolah penelitian ini bisa dijadikan sebagai informasi keadaan budaya membaca peserta didik kelas XII di SMAN 4 Banjarmasin dan dapat menambah pengetahuan tentang pentingnya budaya membaca sebagai upaya meningkatkan kualitas hasil belajar dan pendidikan.

\section{Waktu dan Tempat Penelitian}

Penelitian dilaksanakan pada tanggal 20 Februari 2019 sampai dengan 14 Maret 2019. Adapun tempat penelitian dilaksanakan di SMAN 4 Banjarmasin. 


\section{Target atau Subjek Penelitian}

Populasi dalam penelitian ini adalah seluruh peserta didik kelas XII SMAN 4 Banjarmasin. Peserta didik kelas XII terdiri atas tujuh rombongan belajar di mana ada empat kelas IPA dan tiga kelas IPS. Keseluruhan jumlah peserta didik kelas XII IPA dan IPS, yakni 235 orang. Peneliti mengambil 29 responden dari peserta didik kelas XII jurusan IPA dan 29 responden dari jurusan IPS. Penelitian ini mengggunakan teknik sampel simple random sampling.

\section{Prosedur}

Penelitian ini menggunakan prosedur dengan tahapan yang pertama, melakukan uji coba angket. Kedua, melakukan pengisian angket yang sudah valid. Ketiga, mengumpulkan nilai rapor mata pelajaran Bahasa Indonesia dari semester satu sampai lima.

Data, Instrumen, dan Teknik

\section{Pengumpulan Data}

Data diperoleh dari pengisian angket budaya membaca dan nilai rapor peserta didik. Sumber data diperoleh dari peserta didik kelas XII di SMAN 4 Banjarmasin dan dari bagian kurikulum SMAN 4 Banjarmasin. Instrumen dalam penelitian ini ada dua, yaitu angket untuk mengetahui budaya membaca dan nilai rapor mata pelajaran Bahasa Indonesia mulai semester satu sampai lima untuk mengetahui hasil belajar. Adapun teknik pengumpulan data penelitian dengan cara menyebar angket kepada 58 peserta didik kelas XII IPA dan IPS guna mengetahui budaya membaca.

\section{Hasil dan Pembahasan}

\section{A. Deskripsi Hasil penelitian}

\section{Budaya membaca}

Hasil analisis nilai terendah, tertinggi, mean, dan standar deviasi variabel budaya membaca dapat dilihat di bawah ini.

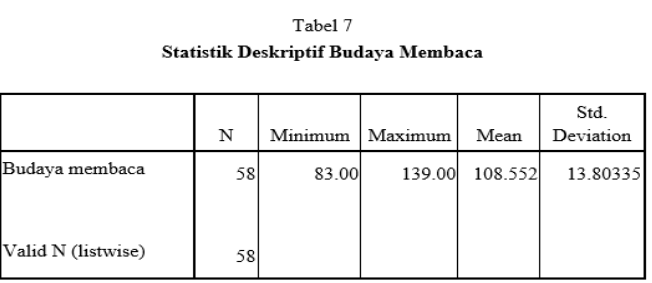

Gambar 1. Tabel 7.

Distribusi tingkat budaya membaca peserta didik kelas XII SMAN 4 Banjarmasin dapat diketahui sebagai berikut.

\begin{tabular}{|l|c|r|l|}
\hline $\begin{array}{c}\text { Rentang Skor } \\
\text { Nilai }\end{array}$ & F & $\begin{array}{c}\text { Per- } \\
\text { sen }\end{array}$ & $\begin{array}{l}\text { Kate } \\
\text {-gori }\end{array}$ \\
\hline $\mathrm{X}<94,75$ & 12 & $\begin{array}{r}20.69 \\
\%\end{array}$ & $\begin{array}{l}\text { Ren- } \\
\text { dah }\end{array}$ \\
\hline $\begin{array}{l}94,75 \leq \mathrm{X} \leq 122,3 \\
6\end{array}$ & 36 & $\begin{array}{r}62.07 \\
\%\end{array}$ & $\begin{array}{l}\text { Se- } \\
\text { dang }\end{array}$ \\
\hline
\end{tabular}




\begin{tabular}{|l|r|r|l|}
\hline$X>122,36$ & 10 & $\begin{array}{r}17.24 \\
\%\end{array}$ & $\begin{array}{l}\text { Ting } \\
\text {-gi }\end{array}$ \\
\hline
\end{tabular}

Tabel 9. Distribusi Frekuensi Budaya Membaca

Berdasarkan tabel 9 di atas, dapat dilihat bahwa tingkat budaya membaca peserta didik berada pada skala sedang dengan pertimbangan rata-rata sebesar 108,55 berada pada selang $94,75 \leq$ $\mathrm{X}<122,36$ (skala sedang). Peserta didik yang memiliki budaya membaca yang rendah sebanyak 12 anak (20,69\%), peserta didik yang memiliki budaya membaca skala sedang sebanyak 36 anak $(62,07 \%)$, dan peserta didik yang memiliki budaya membaca skala tinggi sebanyak 10 peserta didik $(17,24)$.

Dari data di atas dapat kita simpulkan bahwa budaya membaca peserta didik kelas XII SMA Negeri 4 termasuk dalam skala sedang.

\section{Hasil Belajar}

Hasil analisis nilai terendah, tertinggi, mean, dan standar deviasi variabel hasil belajar dapat dilihat di bawah ini.

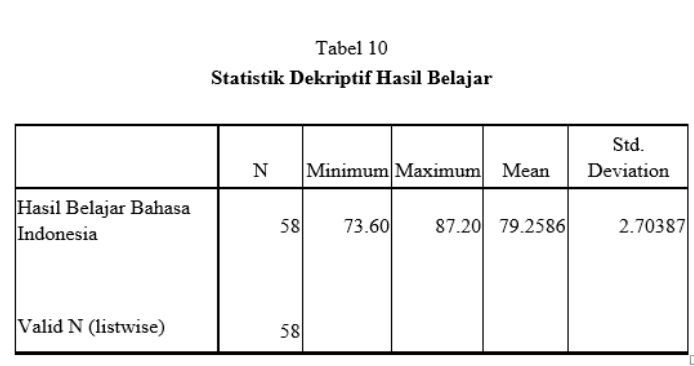

Gambar 2. Tabel 10.

Distribusi tingkat hasil belajar Bahasa Indonesia peserta didik kelas XII SMAN 4 Banjarmasin dapat dilihat sebagai berikut.

Tabel 12

Distribusi Frekuensi Hasil Belajar Bahasa Indonesia

\begin{tabular}{|c|l|r|r|l|}
\hline No & Rentang Skor Nilai & Frekuensi & Persentase & Kategori \\
\hline 1 & $\mathrm{X}<76,55$ & 8 & $13.79 \%$ & Rendah \\
\hline 2 & $76,55 \leq \mathrm{X} \leq 81,97$ & 41 & $70.69 \%$ & Sedang \\
\hline 3 & $\mathrm{X}>81,97$ & 9 & $15.52 \%$ & Tinggi \\
\hline
\end{tabular}

Gambar 3. Tabel 12.

Berdasarkan gambar 3, dapat dilihat tingkat hasil belajar peserta didik pada pelajaran Bahasa Indonesia berada pada tingkatan sedang dilihat dari rata-rata sebesar 79,26 berada pada selang $76,55 \leq \mathrm{X} \leq 81,97$ (tingkatan sedang). Peserta didik yang mendapat hasil belajar Bahasa Indonesia yang rendah oleh peserta didik sebanyak 8 anak $(13,79 \%)$, peserta didik yang mendapat hasil yang sedang pada pembelajaran 
Bahasa Indonesia sebanyak 41 anak $(70,69 \%)$, dan peserta didik yang mendapat hasil yang tinggi pada pembelajaran Bahasa Indonesia sebanyak 9 anak $(15,52 \%)$.

Dari data di atas dapat disimpulkan hasil belajar Bahasa Indonesia pada peserta didik kelas XII di SMAN 4 Banjarmasin termasuk dalam kategori sedang.

\section{B. Uji Prasyarat Analisis}

\section{Uji Normalitas}

\begin{tabular}{|l|c|c|c|} 
Habel 13 \\
\multicolumn{1}{|c|}{ Hasil Uji Normalitas } \\
\begin{tabular}{|l|c|c|c|}
\hline Variabel & Kolmogorov- & Asymp. Sig & Kesimpulan \\
\hline Sudaya membaca $Z$ & 0,465 & 0,982 & Normal \\
\hline $\begin{array}{l}\text { Hasil belajar Bahasa } \\
\text { Indonesia }\end{array}$ & 0,512 & 0,956 & Normal \\
\hline
\end{tabular}
\end{tabular}

Gambar 4. Tabel 13.

Sesuai gambar di atas dapat dilihat dan disimpulkan bahwa hasil perhitungan dari variabel budaya membaca didapat nilai signifikansi sebesar 0,982 dan variabel hasil belajar Bahasa Indonesia didapat nilai signifikansi sebesar 0,956. Maka dari itu, dapat disimpulkan sebaran data dari kedua variabel tersebut terdistribusi normal sehingga memenuhi syarat untuk melakukan pengujian statistik parametrik.

\section{Uji Linearitas}

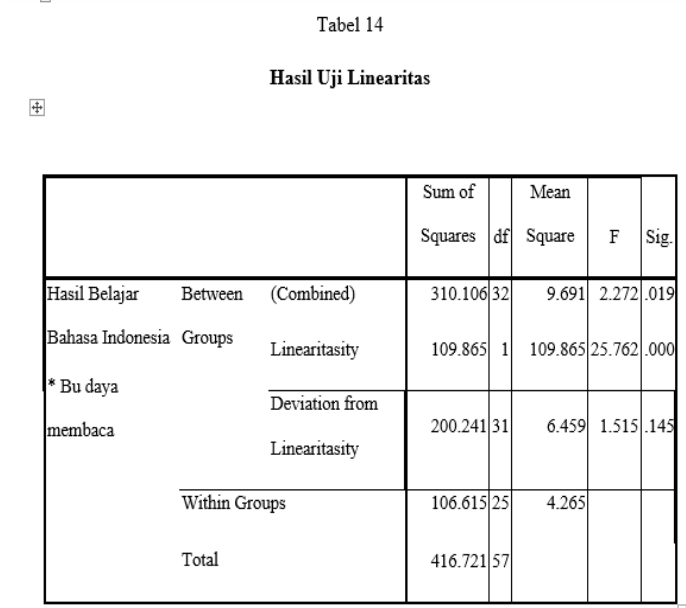

Gambar 5. Tabel 14.

Berdasarkan gambar 5 yang memperlihatkan nilai signifikansi 0,145 lebih besar dari 0,05. Maka hal ini memperlihatkan variabel budaya membaca memiliki hubungan yang linear dengan variabel hasil belajar Bahasa Indonesia.

\section{Pengujian Hipotesis}

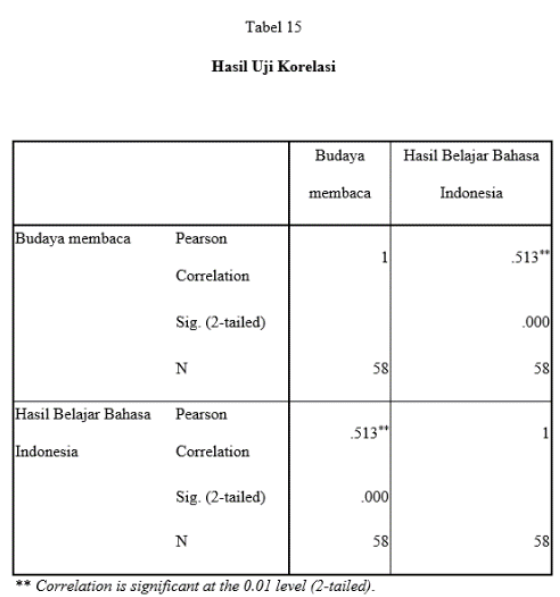


Gambar 5. Tabel 15.

Dengan menggunakan tingkatan signifikansi 5\% didapat nilai rhitung sebesar 0,513 dengan acuan nilai signifikansi $\quad 0,000$. Nilai rhitung yang positif memperlihatkan hubungan yang terjalin di antara kedua variabel positif dan nilai signifikansi lebih kecil dari $5 \%(0,000<0,05)$ yang menunjukkan hubungan antar variabel yang signifikan. Berdasarkan penjelasan di atas, dapat ditarik kesimpulan bahwa Ha yang berbunyi, "Ada hubungan yang positif dan signifikan antara budaya membaca dengan hasil belajar Bahasa Indonesia peserta didik kelas XII di SMAN 4 Banjarmasin" diambil dan Ho berbunyi, "Tidak ada hubungan yang positif dan signifikan antara budaya membaca dengan hasil belajar Bahasa Indonesia peserta didik kelas XII SMAN 4 Banjarmasin” ditolak.

\section{Pembahasan}

Setelah melalui analisis data di atas, diperoleh nilai koefisien korelasi positif, yang menunjukkan hubungan antara budaya membaca dan hasil be- lajar peserta didik pada pelajaran $\mathrm{Ba}$ hasa Indonesia positif. Hasil analisis data sesuai dengan teori dari Djalali (2008: 98-100) bahwa budaya membaca menjadi faktor dari dalam diri yang akan meningkatkan hasil belajar peserta didik.

Namun, perolehan koefisien korelasi sebesar 0.513 terletak dalam golongan yang agak rendah karena berada pada selang 0,400-0,600. Jadi, korelasi positif dan angka korelasi berada dalam golongan agak rendah. Terbukti dengan adanya frekuensi terbanyak untuk variabel budaya membaca pada tahap sedang, yaitu persentase $62,07 \%$ dengan jumlah peserta didik sebanyak 36 anak. Begitu pula dengan hasil pembelajaran Bahasa Indonesia frekuensi terbanyaknya ada pada tingkat sedang, yaitu persentase $70,69 \%$ dengan jumlah peserta didik sebanyak 41 anak.

Hasil analisis juga menunjukkan korelasi antara kedua jenis variabel signifikan karena menunjukkan nilai signifikansi lebih rendah dari $5 \%(0,000<0,05)$. Jadi, hasil penelitian ini menunjukkan peran budaya membaca peserta didik memberikan dampak yang baik terhadap hasil 
pembelajaran Bahasa Indonesia. Jika budaya membaca yang dimiliki rendah maka akan mengakibatkan peserta didik mengalami kesulitan dalam belajar Bahasa Indonesia.

Berdasarkan hasil analisis di atas, maka Ha diambil dan Ho dibuang. Ha diambil dalam penelitian ini, yaitu: ada hubungan baik dan signifikan antara budaya membaca dengan hasil pembelajaran Bahasa Indonesia peserta didik kelas XII di SMAN 4 Banjarmasin.

\section{Simpulan dan Saran}

1. Budaya membaca peserta didik kelas XII SMAN 4 Banjarmasin memiliki nilai rata-rata 108,55. Pemerolehan nilai tersebut menunjukan bahwa budaya membaca peserta didik tergolong kategori sedang.

2. Hasil belajar Bahasa Indonesia kelas XII SMAN 4 Banjarmasin memiliki rata-rata sebesar 79,26. Pemerolehan nilai tersebut menunjukan bahwa hasil belajar Bahasa Indonesia tergolong kategori sedang.

3. Dengan menerapkan taraf signifikansi $5 \%$ didapat nilai rhitung sebesar 0,513 dengan nilai signifikansi 0,000 . Nilai rhitung yang positif menunjukkan hubungan yang terjadi di antara kedua variabel adalah positif dan nilai signifikansi lebih kecil dari $5 \%(0,000<0,05)$ yang berarti bah-wa hubungan antar kedua variabel juga signifikan. Hasil rhitung yang diperoleh kemudian diinterpretasikan ke dalam tabel. Nilai $r$ berada di antara selang 0,400 sampai dengan 0,600 dengan interpretasi agak rendah. Jadi, terdapat korelasi yang positif dan signifikan kategori agak rendah antara budaya membaca dengan hasil belajar peserta didik pada pelajaran Bahasa Indonesia kelas XII SMAN 4 Banjarmasin.

Berdasarkan hasil penelitian, baik dari pemerolehan data yang didapat maupun dari peneliti, maka dapat diberikan beberapa saran, yaitu:

1. Hendaknya peserta didik memulai kebiasaan membaca agar memiliki budaya membaca 
yang tinggi dan dapat meningkatkan hasil belajar.

2. Guru dapat meningkatkan budaya membaca peserta didik dengan menambah jam kunjungan ke perpustakaan atau memberi PR yang berkaitan dengan membaca.

3. Pihak sekolah dapat mendukung usaha untuk meningkatkan budaya membaca peserta didik menjadi kategori tinggi dengan mulai menjalankan lagi program Kemendikbud, yaitu program Lima Belas Menit Membaca, memerhatikan fasilitas penunjang lainnya, seperti menambah jumlah koleksi buku di perpustakaan, membuat perpustakaan menjadi tempat yang menarik untuk dikunjungi peserta didik, membuat perpustakaan kecil di dalam kelas, dll. Hal ini sangat penting dilakukan agar dapat memotivasi peserta didik untuk membaca.

4. Orang tua dapat mencontohkan kepada anak dalam hal budaya membaca agar lebih mudah membentuk budaya membaca sejak dini karena hal pertama yang ditiru anak adalah kebiasaan orang tuanya.

5. Bagi penelitian selanjutnya disarankan untuk meneliti faktor lain yang memengaruhi hasil belajar sesuai dengan teori yang sudah ada atau meneliti isu lainnya yang membuat keberhasilan dalam proses belajar agar penelitian yang dilakukan tidak ketinggalan zaman.

\section{Daftar Rujukan}

Fadhli, Anggi, Jolianis, Mareta Kemala Sari. (2016). "Pengaruh Budaya Membaca, Pendidikan Karakter, dan Efikasi Diri Terhadap Hasil Belajar Pada Mata Pelajaran Ekonomi Kelas X SMAN 12 Padang." Diakses tanggal 28 Maret 2018 dari (http://jim.stkip-pgrisumbar.ac. id).

Ghozali, Hanafi, I Komang Winata, Nurdin. (2013). "Pengaruh Budaya Membaca, Motivasi Belajar, dan Cara Belajar Terhadap Hasil Belajar Ekonomi." Dalam Jurnal Edukasi Ekobis. Vol. 1 No. 8. Diakses tanggal 25 Maret 2018 dari (http://jurnal.fkip.unila. ac. id).

Hamalik, Oemar. (2008). Proses Belajar Mengajar. Jakarta: Bumi Aksara.

Huda, Nizlel. (2013). “Analisis Faktor-faktor Dominan yang Memengaruhi Hasil Belajar Mate- 
matika Siswa SMPN 1 Muaro

Jambi." Dalam Jurnal Sains dan Matematika Vol. 1 No. 2. Diakses tanggal 27 Maret 2018 dari (http://onlinejournal.unja. ac.id).

Ismaya, Rita, R., Gunawan Sudarmanto, Nurdin. (2013). "Pengaruh Kemandirian Bela-jar, Cara Belajar dan Budaya Membaca terhadap Hasil Belajar." Dalam Jurnal Edukasi Ekobis Vol. 1 No. 2. Diakses tanggal 27 Maret 2018 dari (http://jurnal.fkip.unila.ac.id).

Jane, Octroaica Cempaka. (2013). "Peran Taman Bacaan Masyarakat dalam Menumbuhkan Budaya membaca Anak di Taman Bacaan Masyarakat 'Mortir' Banyumanik-Semarang." Dalam Jurnal Ilmu Perpustakaan Vol. 2, No. 2. Diakses tanggal 28 Maret 2018 dari (http://journal.student.uny.ac. id).

Purchan, Arief. (1982). Pendekatan Penelitian dalam Pendidikan. Surabaya: Usaha Nasional.

Sugiyono. 2016. Metode Penelitian Kuantitatif, Kualitatif, dan $R \& D$. Bandung: Alfabeta.

Sujarweni, Wiratna. Poly Endrayanto. (2012). Statistik Untuk Penelitian. Yogyakarta: Graha Ilmu.

Sulistyo, Andri. (2017). "Evaluasi Program Budaya Membaca di Sekolah Dasar Negeri." Dalam Jurnal Kelola Vol. 4 No. 1. Diakses tanggal 21 Maret 2018 dari (http://ejournal.uksw.edu).

Sutarno. (2005). Belajar dan Faktorfaktor yang Mempengaruhinya. Bandung: Alfabeta. 